\title{
INFLUENCE OF THE RECLAMATION METHOD OF SPENT MOULDING SANDS ON THE POSSIBILITY OF CREATING FAVOURABLE CONDITIONS FOR GASES FLOW IN A MOULD
}

\begin{abstract}
The results of investigations concerning the influence of the applied sand matrix (fresh sand, reclaim) on the properties of moulding sands used for production of large dimensional castings (ingot moulds, ladles), are presented in the hereby paper. The performed investigations were aimed at determining the influence of various reclamation methods of spent moulding sands on the quality of the obtained reclaimed material. Moulding sands were prepared on the fresh quartz matrix as well as on sand matrices obtained after various reclamation methods. The selected moulding sand parameters were tested (strength, permeability, grindability, ignition losses, $\mathrm{pH}$ reactions). It can be stated, on the basis of the performed investigations, that the kind of the applied moulding sand matrix is of an essential meaning from the point of view of creating conditions minimising formation of large amounts of gases and their directional migration in a casting mould.
\end{abstract}

Keywords: spent moulding sands, mechanical reclamation, thermal reclamation, organic binders, ignition losses

\section{Introduction}

Spent moulding sands, after making a casting are utilised in various ways. The most often they are either subjected to a mechanical reclamation process or, less often, to a thermal reclamation, or they are used in other industrial sectors. In extreme situations spent moulding sands are transported to damping grounds, which from economical as well as ecological reasons is very wrong [1]. The problem of the spent moulding sands management is specially important for companies producing high-dimensional castings since amounts of used moulding sands are very large. Therefore efforts of as long as possible usage of the given quartz matrix in the foundry are undertaken by selecting methods and intensities of purification operations [2]. The reclamation process consists of several operations: disintegration of spent moulding sands into individual grains, removal of metal parts and contaminations originated from the pouring process, removal of binder coatings from grain surfaces - „secondary reclamation" and - finally - dedusting of technologically unsuitable fractions (formed due to applied purification processes) [3]. The mechanical reclamation is the simplest and the cheapest way of a quartz sand reclamation. This method is applied mainly to classic moulding sands and with water glass, but it is also used for spent moulding sands with organic binders. In majority of such cases mainly a disintegration of spent moulding sands to individual grains is obtained as well as a removal - from grain surfaces - a part of degradation and thermal destruction products formed due to the contact and thermal influence of liquid metal on a mould inside. Nearly total removal of organic binders from surfaces of sand grains occurs in thermal reclaimers. Investigations presented in papers $[4,5]$ indicated that certain contaminations can gather in surface irregularities of quartz matrices and can not be removed from there by the mechanical method. In thermal reclaimers operating with using a fluidised bed (the most often applied) gaseous products of organic binders decompositions as well as burned products (ashes) are removed during the air blowing through this bed. The purification degree of a matrix subjected to the thermal reclamation and typical supplementing treatments is very high - comparable with the fresh sand matrix. An additional advantage of the thermally reclaimed sand is the stabilisation of its volumetric dilatability under a temperature influence, related to the quartz allotropic change [6,7].

The known European producer of massive high-dimensional castings (ladles and ingot moulds) of spheroidal and vermicular cast iron is battling with problems of uneven cast iron structure occurrence and with defects related to gassing on casting walls cross-sections. This state is connected with a significant difference in cooling rates between intensively cooling external layers of product walls (having access to surroundings and thus better conditions to heat scattering) and slowly cooling metal layers from the casting core side, which form a closed space. This situation causes that obtained spent moulding sands are with varying degrees of burnout. The analysis of effects obtained due to the mechanical and thermal reclamation of the spent furan moulding

\footnotetext{
AGH UNIVERSITY OF SCIENCE AND TECHNOLOGY, FACULTY OF FOUNDRY ENGINEERING, 23 REYMONTA STR., 30-059 KRAKÓW, POLAND

Corresponding author: eumar@agh.edu.pl
} 
sand applied in the foundry plant, is presented in this paper. The reclaimed material obtained from spent moulding sands with organic binder was subjected to assessments with the application of several criteria recommended for the quality identification of the grain matrix achieved after purification operations [7-9]. The performed analysis was aimed at determining the quality of applied materials in respect of their suitability for production of large moulds, in which conditions for controlling casting cooling rates - with taking into account the directional mould degassing - will be created. One of the elements, which can influence this aim, is the creation of favourable conditions for carrying away of gases by means of selecting the proper materials, which can provide the determined permeability of the applied moulding sand. The successive important element, within the considered aspect, especially when the moulding sand with the organic binder is used, is its gas volume emission rate (dependent on the resin quantitative fraction in the moulding sand [10]), influencing the rate and possibility of carrying away of gases from the mould. Manufacturer predicted to create a virtual model of a foundry in order to analysis flows of reclamation sand [11]

\section{Materials}

Fresh sand and the mechanical reclaim taken from the technological line in the foundry plant was used as the grain matrix. The binder used in the foundry (furan resin FR-75A - 1 part of moulding sand) and hardener PU-6 (mixture of sulphonic and inorganic acids modified by special additions) in amount of $45 \%$ in relation to resin, were used for preparing moulding sands.

\section{Devices applied in investigations}

The mechanical reclamation was realised in the device used in the foundry plant. The schematic presentation of this mechanical reclaimer is given in Fig. 1. The principle of operation was presented in paper [7].

The thermal reclamation of investigated materials was performed in the experimental thermal reclaimer with fluidised bed, made according to the concept and design of the author [12-14]. The device is shown in Fig. 2. The reclamation process was realised in the thermal reclaimer after its preliminary warming to the operation temperature. Achieving the fluidisation air temperature of $50^{\circ} \mathrm{C}$ was assumed as the criterion of the heat accumulation by the device. When the needed temperature of $600^{\circ} \mathrm{C}$ was obtained, $10 \mathrm{~kg}$ of the tested material was charged into the device. At the determined time intervals small samples were taken through the outlet for testing ignition losses. The reclamation tests were performed for spent moulding sands prepared of a fresh quartz matrix, for mechanical reclaims and also for spent moulding sands prepared of mechanical reclaims.

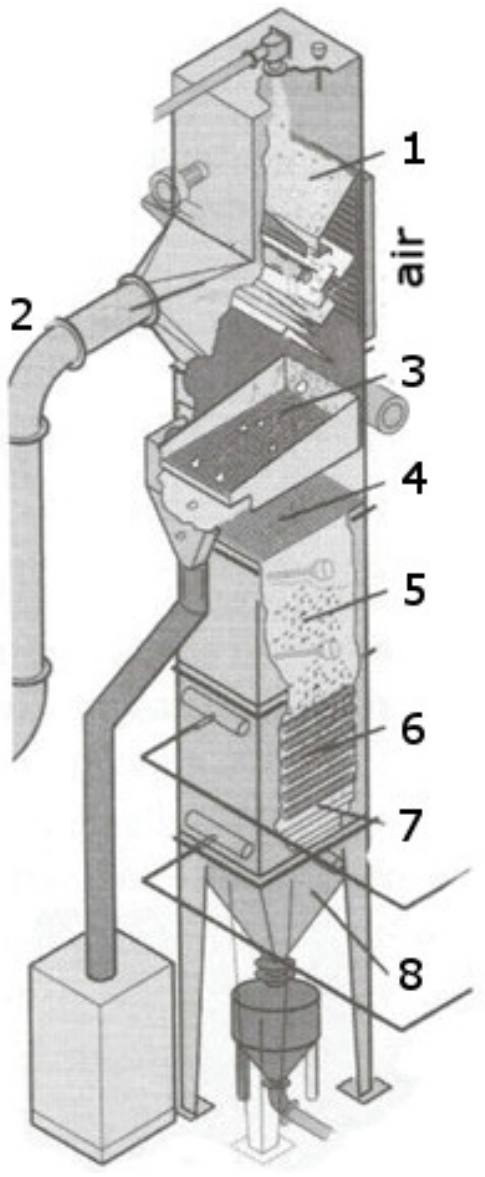

Fig. 1. Scheme of the tower reclaimer applied in mechanical reclamation systems of the IMF Company: 1 - reclamation chamber, 2 - exhaust of dusted air, 3 - vibratory screen, 4 - stationary sieve, 5 - cooling chamber, 6 - water cooler, 7 - thermostatic valve, 8 - outlet [7]

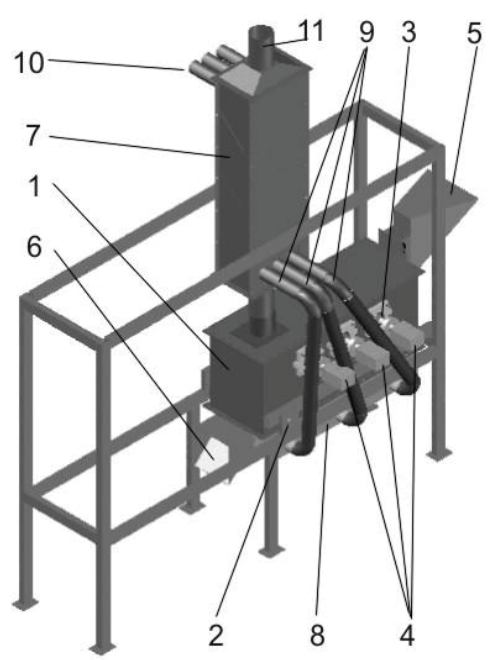

a)

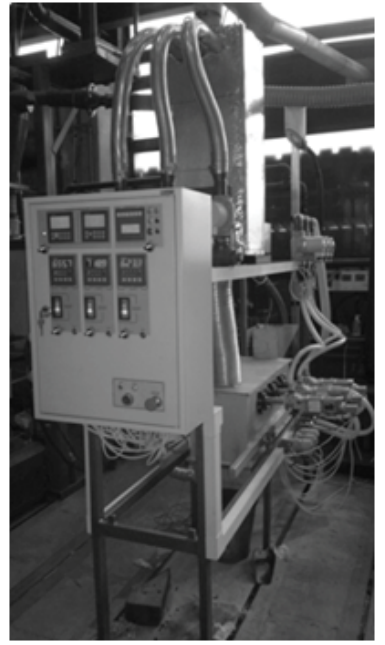

b)
Fig. 2. Experimental thermal reclaimer: a) Scheme 1 - reclaimer chamber, 2 - supporting bearing for chamber tilting, 3 - articulated burner seat, 4 - burners, 5 - moulding sand charge, 6 - reclaim outlet, 7 recuperator, 8 - fluidising chamber divided into sections, 9 - conduits supplying warmed air for fluidisation, 10 - air intake for fluidisation, 11 - combustion gases outlet, b) View of the reclaimer stand 


\section{Investigation methods}

\subsection{Mass decrements - ignition losses}

The sampled materials were tested for ignition losses. The organic binder content in the fresh grain matrix or in the reclaim was assessed for two $30 \mathrm{~g}$ samples weighted into quartz crucibles. Tests were performed at a temperature of $950^{\circ} \mathrm{C}$. The presented here data are averaged from two results. The ignition time of samples was 2 hours.

\subsection{Sieve analysis}

The sieve analysis was performed for two $50 \mathrm{~g}$ samples. Sieving was done on the laboratory shaker LPeZ-2e. Results were worked out by the program LabaSit.

\subsection{Determination of the $\mathrm{pH}$ reaction}

The $\mathrm{pH}$ value of the tested material was determined on $50 \mathrm{~g}$ sample into which $50 \mathrm{~cm}^{3}$ of distilled water was added, then mixed and left for 1 hour. The $\mathrm{pH}$ value was determined by means of the microcomputer $\mathrm{CP}-105 \mathrm{pH}-$ meter. The measurement was done after the calibration of the device, levelling an eventual error related to electrode properties. Two buffer solutions of strictly determined $\mathrm{pH}$ values are necessary for the calibration, e.g. for acidic contaminated waters of values: $7 \mathrm{pH}$ and $4 \mathrm{pH}$.

\subsection{Investigations of the moulding sands strength after hardening}

The moulding sand of a constant composition of resin and hardener was prepared from the fresh sand matrix and reclaimed materials obtained as a result of the application of various treatments of spent moulding sands. Samples for strength testing were compacted in the vibratory device LUZ-1. After 1 hour and after the total 24 hours of hardening the bending strength was tested. The presented results are averaged from three measurements. The strength investigations were realised by means of the universal device for strength measurements $\mathrm{LRu}-2 \mathrm{e}$.

\subsection{Permeability testing}

The permeability testing was performed on roll shaped elements in the device for measurements the moulding sands permeability: LPiR-3e.

\subsection{Computer tomography}

As it was mentioned in the introduction, the reclamation treatment consists of several operations, among others, the separation of the metal parts of various origin. Small metal particles are mainly formed during the pouring process, but also appear in spent moulding sands due to the application of the shot blasting method for castings purifications. Therefore, in order to determine homogeneity and purity of reclaimed materials used in the casting moulds production the computer tomography investigations were performed. This type of investigations allows to reveal all density changes of the tested materials and in the case of moulding sands metal inclusions originated from the cast alloys. The computer image of tested shaped elements was prepared by means of the iCAT tomograph, applying the total $360^{\circ}$ scanning and the most accurate scanning beam being $0.125 \mathrm{~mm}$ in all axes.

\section{Investigation results}

Ignition losses of grain matrices (fresh sand, mechanical reclaim) and moulding sands prepared on them, are presented in Fig. 3. It was found that the mechanical reclaim taken from the foundry plant is covered with a significant amount of spent binders, and its amount is higher than on the moulding sand grain matrix prepared of fresh sand. Multicyclic circulation of the moulding sand prepared only of the reclaim obtained by the mechanical method causes gathering significant amounts of the hardened binder on grains surfaces. Since the moulding sand after pouring is burned to a small degree only, the mechanical reclamation is not able to remove the resin layer covering matrix grains. The moulding sand prepared on such matrix is characterised by more than twice higher amount of bound binders. It is undoubtedly the factor increasing the moulding sand gas volume emission, hindering an efficient mould degassing.

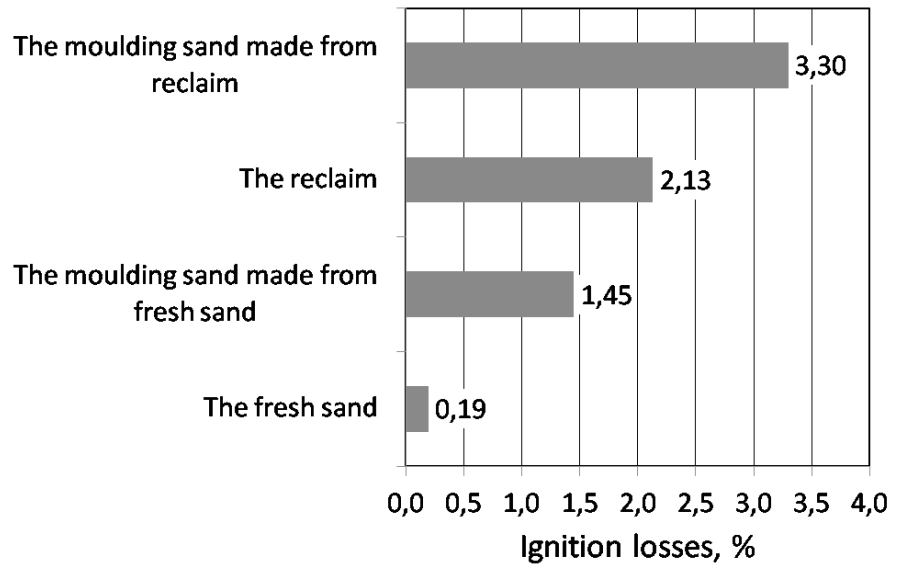

Fig. 3. Ignition losses of grain matrices and moulding sands prepared on them 


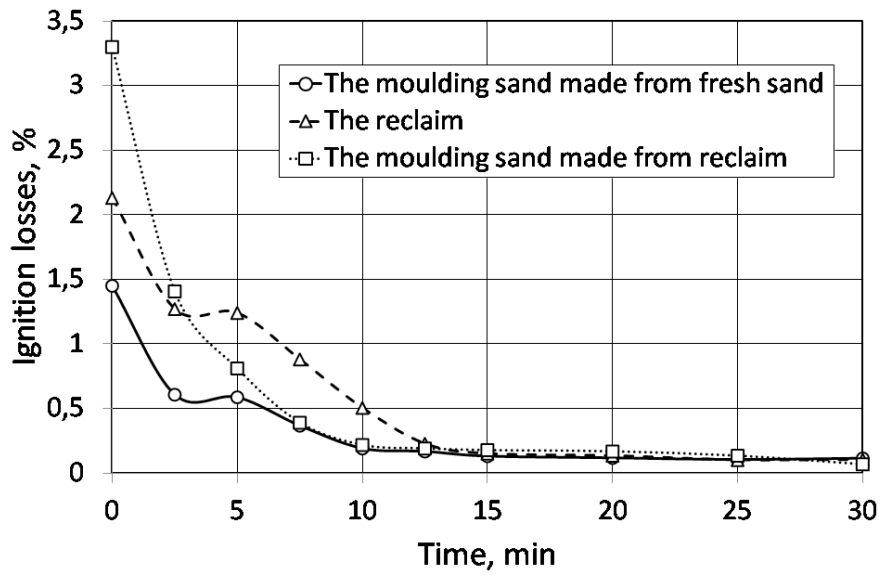

Fig. 4. Comparison of ignition losses of the reclaimed materials

The results of the performed investigations of the thermal reclamation are shown in Fig. 4. The thermal reclamation results of the moulding sand prepared of fresh components are also in this diagram. Investigations of the thermal reclamation of the spent moulding sand prepared on the fresh matrix were carried out as the reference point for the thermal reclamations of the reclaim obtained by the mechanical method and for the spent moulding sand prepared on the matrix of the mechanical reclaim. In all three cases, it was found that - despite different initial ignition losses - after approximately 15 minutes of the thermal reclamation process (realised at a temperature of $600^{\circ} \mathrm{C}$ ), values of ignition losses stabilise on the level app. $0.1 \%$. It is possible to notice - in Fig. 4 - the essential problem that the liquid metal influence on the mould causes a partial pyrolysis of a binder and this prolongs the organic binder destruction time (which can be observed in case of the thermal reclamation of the mechanical reclaimer).

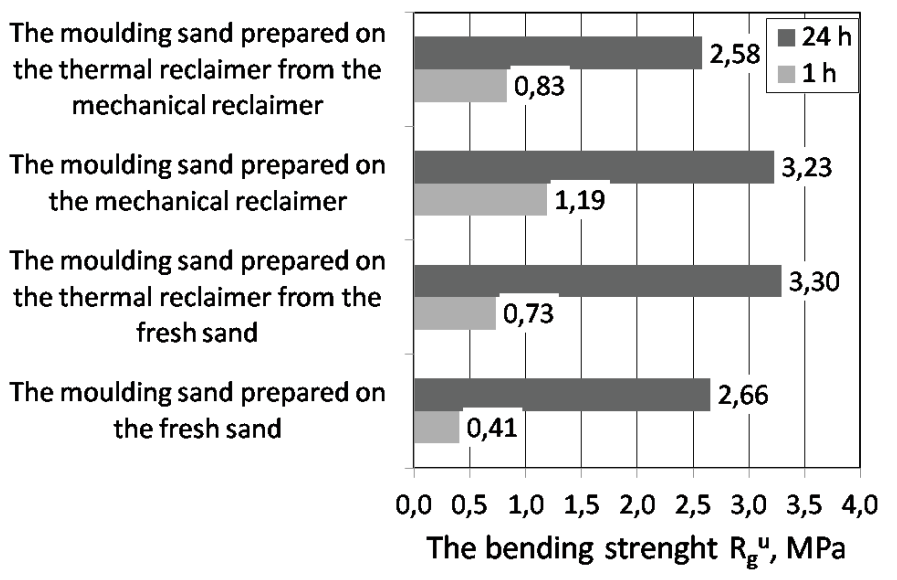

Fig. 5. Comparison of the strength of moulding sands prepared on various matrices

The results of bending strength investigations of moulding sands prepared on various matrices are shown in Fig. 5. Investigations indicate that the moulding sand prepared on the fresh sand matrix is binding in the slowest way. Making shaped elements for strength tests from the moulding sand prepared on the thermal reclaimer matrix obtained from the fresh moulding sand shortens their service time, but after their total hardening the higher strength is obtained. The moulding sand prepared on the grain matrix of the reclaim obtained by the mechanical method is the fastest binding. An additional treatment of the thermal reclamation favours the moulding sand service life improvement, but also decreases its final strength which achieves the value comparable with the moulding sand made of the fresh sand.

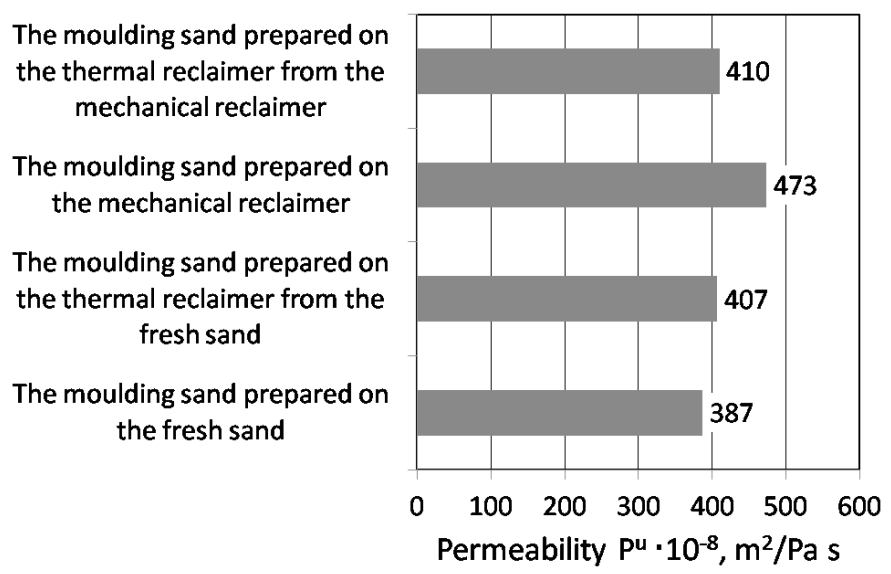

Fig. 6. Comparison of the permeability of moulding sands prepared on various matrices

The results of the moulding sands permeability are shown in Fig. 6. The best permeability was found for the moulding sand prepared on the grain matrix of the reclaim obtained by means of the mechanical treatment. This can be explained by better rounding of grains (surface unevenness filled by a binder) and by larger grains diameters. However, it should be kept in mind, that this increased permeability can be - in a final effect - compensated by a higher gas evolution from the moulding sand.

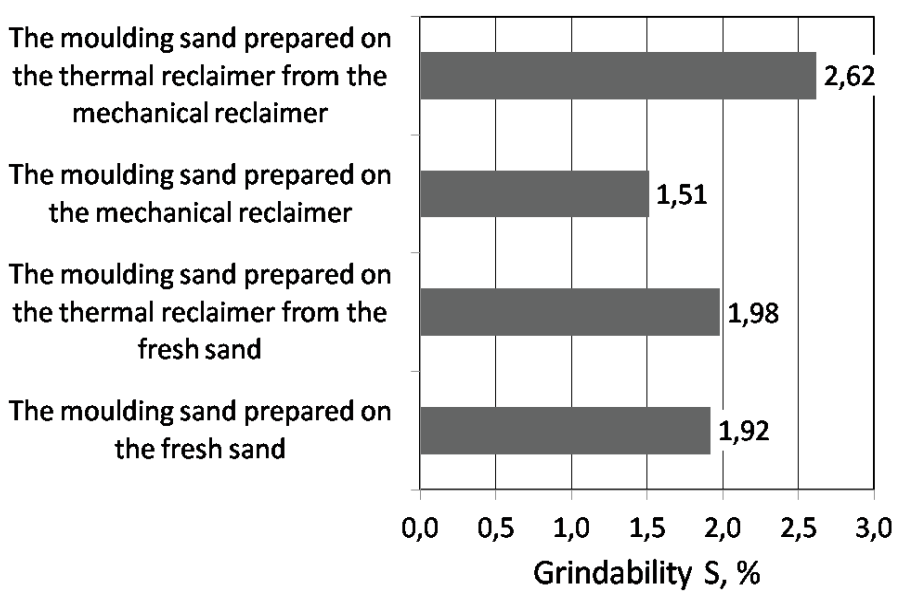

Fig. 7. Comparison of the grindability of moulding sands prepared on various matrices

The grindability results of moulding sands prepared on various grain matrices are presented in Fig. 7. The highest grindability was found for the moulding sand prepared from the reclaimed material after the mechanical and thermal reclamation. 
The thermal reclamation of the spend moulding sand prepared of the reclaim after the mechanical...

The reclaimed material after the mechanical reclamation

The thermal reclamation of the spent moulding sand from fresh sand

The fresh sand

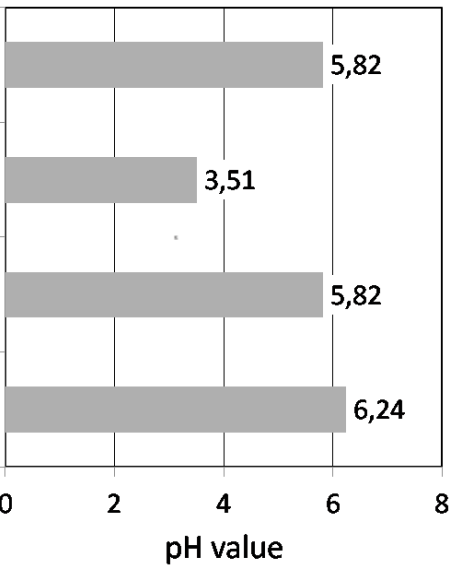

Fig. 8. Comparison of $\mathrm{pH}$ reactions of tested materials

It was found that the fresh matrix has the least acidic reaction (Fig. 8). The reclaim obtained by the mechanical method has the most acidic reaction. Therefore the strength of the mould- ing sand prepared of the mechanical reclaim is the highest, but simultaneously the service life shortens - this moulding sand is faster binding. The thermal reclamation of the spent moulding sand from fresh sand as well as the moulding sand prepared of the reclaim after the mechanical treatment causes decreasing of the matrix acidity and maintains $\mathrm{pH}$ values on the comparable level. This causes the binding rate decrease but does not decrease radically the permeability (lower binder amount - lower gas evolution from a moulding sand). Analysing the grain matrix quality the computer tomographic investigations were performed of shaped elements made of the fresh matrix and of the mechanical reclaim. None essential changes in the RTG image were noticed in the fresh sand (Fig. 9).

However, in the tomographic image of the shaped element prepared of the mechanical reclaim several bright spots - indicating contaminations - are seen (Fig. 10). It can be expected that their majority constitute small metal particles (created during the pouring process and at casting knocking out).
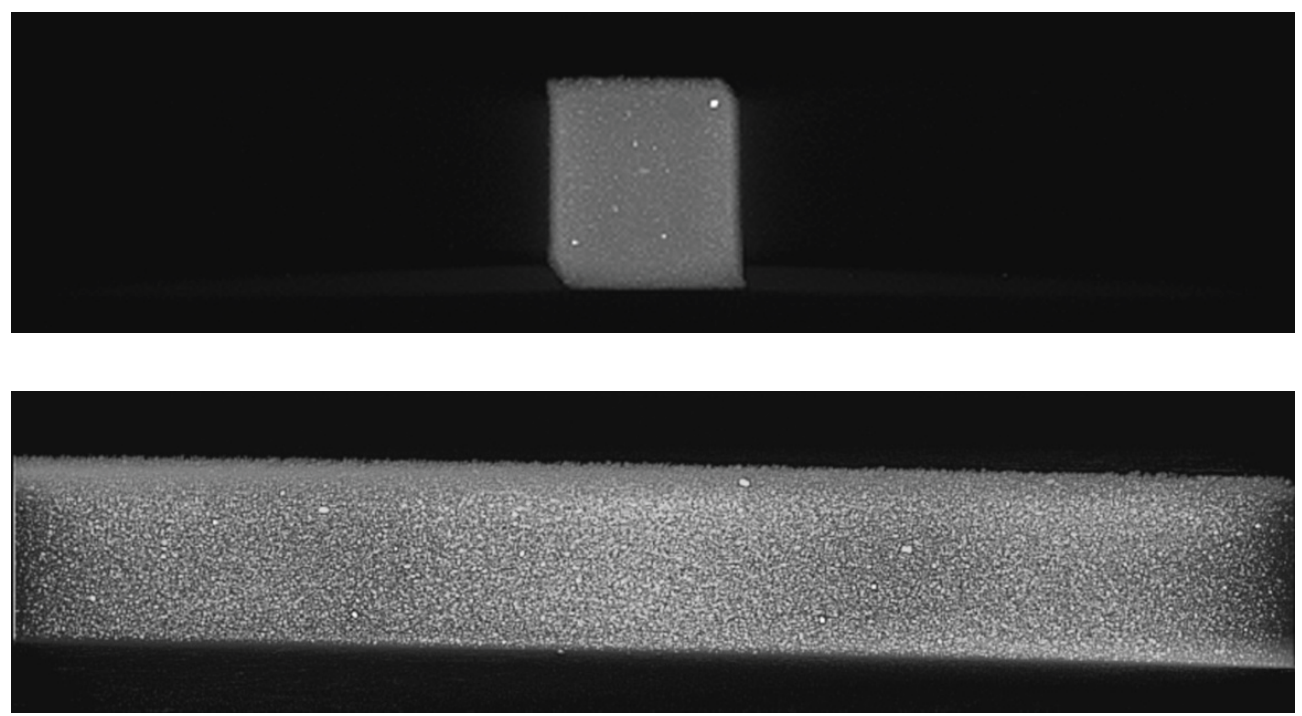

Fig. 9. Tomographic image of the specimen for strength tests made of the fresh sand (view in two projections)
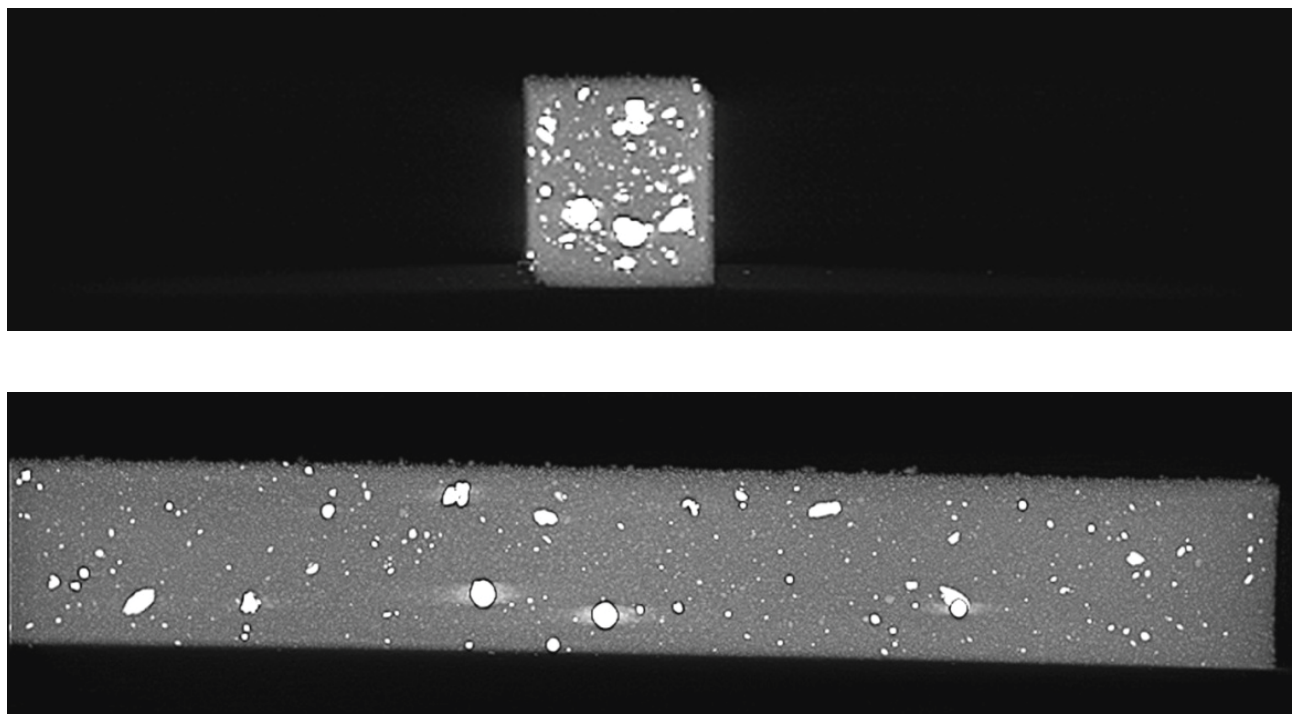

Fig. 10. Tomographic image of the specimen for strength tests made of the reclaim obtained by mechanical method (view in two projections) 


\section{Conclusions}

As the result of the performed investigations it can be stated that the kind of the matrix applied for preparing moulding sands is essential from the point of view of the possibility of the directional degassing of the mould. The less binder in a moulding sand the higher possibility of obtaining sound castings. Therefore in case of foundry plants producing massive castings (ladles, ingot moulds) the thermal reclamation application should be considered. Expenses incurred for a complete purification of grain matrices from binders, left from the previous technological cycles, can bring measurable benefits in the sound castings production. The performed investigations clearly indicate that in the situation of the foundry plant, in which spent moulding sands of various burning degrees remain after the casting knocking out, the only rational solution is the application of the thermal reclamation. Nevertheless special attention should be directed to economic and ecological aspects of the thermal reclamation. The process should be optimized in respect of the process time and temperature. Too high reclamation temperature makes process more costly not warranting achieving good effects, i.e. better purification of grain matrices from organic binders.

\section{Acknowledgements}

This work was elaborated under research and development study no 11.11.170.318, task 2

\section{REFERENCES}

[1] I. Izdebska-Szanda, Z. Maniowski, F. Pezarski, Archives of Foundry Engineering 10, 2, 71-76 (2010).

[2] M. Lucarz, Metalurgija 47, 1, 43-45 (2008).

[3] M. Łucarz, Opracowanie podstaw regeneratorów odśrodkowych, Praca doktorska, Kraków, 1996

[4] M. Łucarz, Metalurgija 45, 1, 37-40 (2006).

[5] M. Łucarz, Archives of Foundry Engineering 10, 2, 93-98 (2010).

[6] J.L. Lewandowski, Wydawnictwo „Akapit”, Kraków, 1997.

[7] J. Dańko, R. Dańko, M. Łucarz, Wydawnictwo Naukowe „Akapit”, Kraków, 2007.

[8] J. Danko, M. Holtzer, R. Dańko, Archives of Foundry Engineering 10, 2, 27-31 (2010)

[9] R. Dańko, Strength model of self-setting moulding sands with synthetic resins in an aspect of the integrated matrix recycling process, Archives of Foundry Engineering, Katowice-Gliwice, 2012.

[10] R. Dańko, Archives of Foundry Engineering 12, 1, 21-26 (2012).

[11] M Brzeziński, A. Stawowy, R. Wrona, Arch Metall Mater 58, 3, 867-870 (2013).

[12] M. Łucarz, Archives of Foundry Engineering 12, 1, 125-130 (2012).

[13] M. Łucarz, Arch Metall Mater 58, 3, 923-926 (2013).

[14] M. Łucarz, Archives of Foundry Engineering 13, 1, 103-106 (2013). 